\title{
5. The effects of Antihypertensive Drugs on Serum Lipids and Lipoproteins in patients with Mild to Moderate Hypertension
}

\author{
Yuichiro GOTO and Hiromitsu TAMACHI
}

Department of Internal Medicine, Tokai University School of Medicine, Bohseidai, Isehara

The purpose of antihypertensive therapy is to prevent the development and exacerbation of complications in target organs, such as the brain, heart and kidney. Thus, the efficacy of an antihypertensive drug should be based on the reduction in these complications as well as the frequency and severity of side effects. From this point of view, several clinical trials to assess the benefits of long-term treatment with antihypertensive drugs have been performed in Western countries (1-8). They have shown a significant reduction in the incidence of stroke, congestive heart failure, renal failure and aneurysmal rupture, but little effect on coronary heart disease (CHD), although hypertension is one of the three major risk factors for CHD. It has been proposed that antihypertensive drugs may have an adverse effect on plasma lipids and lipoproteins metabolism, offsetting their beneficial effects in CHD. To evaluate this hypothesis, the relationship between changes in lipids and lipoproteins and the incidence of $\mathrm{CHD}$ in long-term antihypertensive drug therapy must be investigated. Unfortunately few reports have examined this correlation, and consequently little information is available for determining the extent to which changes in lipids or lipoproteins contribute to CHD. Therefore, we have summarized the effect of antihypertensive drugs on lipids by reviewing published reports, including our own, and analyzed these changes in terms of the probability of developing CHD using the published risk table (9). It is important to appreciate the significance of small changes in serum cholesterol and establish criteria for the selection of antihypertensive drugs.

We reviewed 44 reports on diuretics, 46 on $\beta$ blockers without intrinsic sympathomimetic activity (ISA), 17 on $\beta$-blockers with ISA, 10 on $\alpha$ - $\beta$ blockers, 21 on $\alpha_{1}$-blockers, 5 on $\alpha_{2}$-agonists, 5 on other antiadrenergic drugs, 8 on $\mathrm{Ca}^{++}$-antagonists and 6 on angiotensin converting enzyme inhibitors (ACE inhibitors). Table 1 summarizes the effects of these drug therapies on serum

Table 1. Effects of Antihypertensive drugs on Serum lipids and Lipoproteins

\begin{tabular}{|c|c|c|c|c|c|c|}
\hline Agents & & $\mathrm{T}$. & chol. & TG & $\mathrm{HDI}-\mathrm{C}$ & LDL-C \\
\hline Thiazide type diuretics & $\begin{array}{l}\text { (Bendroflumethiazide, Chlorthalidone, } \\
\text { Polythiazide) }\end{array}$ & $\uparrow \uparrow$ & $\sim$ & $\uparrow \uparrow$ & $\sim \downarrow$ & $\uparrow \uparrow$ \\
\hline $\begin{array}{l}\text { Loop diuretics Spironolactone } \\
\text { B-blocker }\end{array}$ & (Furosemide, Mefurside) & & $\downarrow$ & $\uparrow \downarrow$ & $\downarrow \downarrow$ & $\uparrow$ \\
\hline ISA $\quad(-)$ & $\begin{array}{l}\text { (Propranolol, Nadorol, Thimolol, } \\
\text { Sotalol, Atenolol, Metoprolol) }\end{array}$ & $\uparrow \uparrow$ & $\sim$ & $\uparrow \uparrow$ & $\downarrow \downarrow$ & $\uparrow \uparrow ح$ \\
\hline ISA $\quad(+)$ & (Oxprenolol, Pindolol, Acebutolol) & $\downarrow$ & $\sim$ & $\uparrow \downarrow$ & $\uparrow \downarrow$ & $\sim$ \\
\hline$\alpha-\beta-b l o c k e r$ & (Labetalol, Bunitrolol) & $\downarrow$ & $\sim$ & $\uparrow \downarrow$ & $\sim \downarrow \downarrow$ & $\downarrow$ \\
\hline$\alpha_{1}$-blocker & (Prazosin, Bunazosin, Terazosin, Doxazosin) & $\downarrow \downarrow$ & $\sim$ & $+\downarrow \sim$ & $\uparrow \uparrow ح$ & $\downarrow \downarrow$ \\
\hline$\alpha_{2}$-agonist & (Guanabenz, Guanfacine) & $\downarrow \downarrow$ & & $\sim$ & $\sim$ & $\downarrow$ \\
\hline Other antiadrenergic & (Methyldopa, Clonidine) & $\uparrow$ & $\sim$ & $\sim$ & $\downarrow \downarrow$ & $\downarrow \downarrow$ \\
\hline $\mathrm{Ca}^{\#}$-antagonist & $\begin{array}{l}\text { (Verapamil, Nifedipine, Diltiazem, } \\
\text { Nicardipin) }\end{array}$ & 2 & & $\sim$ & $\sim$ & 2 \\
\hline ACE inhibitor & (Captopril, Enarapril) & $\downarrow \downarrow$ & $\sim$ & $\sim \psi$ & $\uparrow ح$ & 2 \\
\hline
\end{tabular}

$\uparrow \uparrow \downarrow \downarrow$ : statistically significant change,

$\uparrow \downarrow$ : small change,

ح: no change 
Table 2. Antihypertensive drug therapy and the probability of coronary heart disease

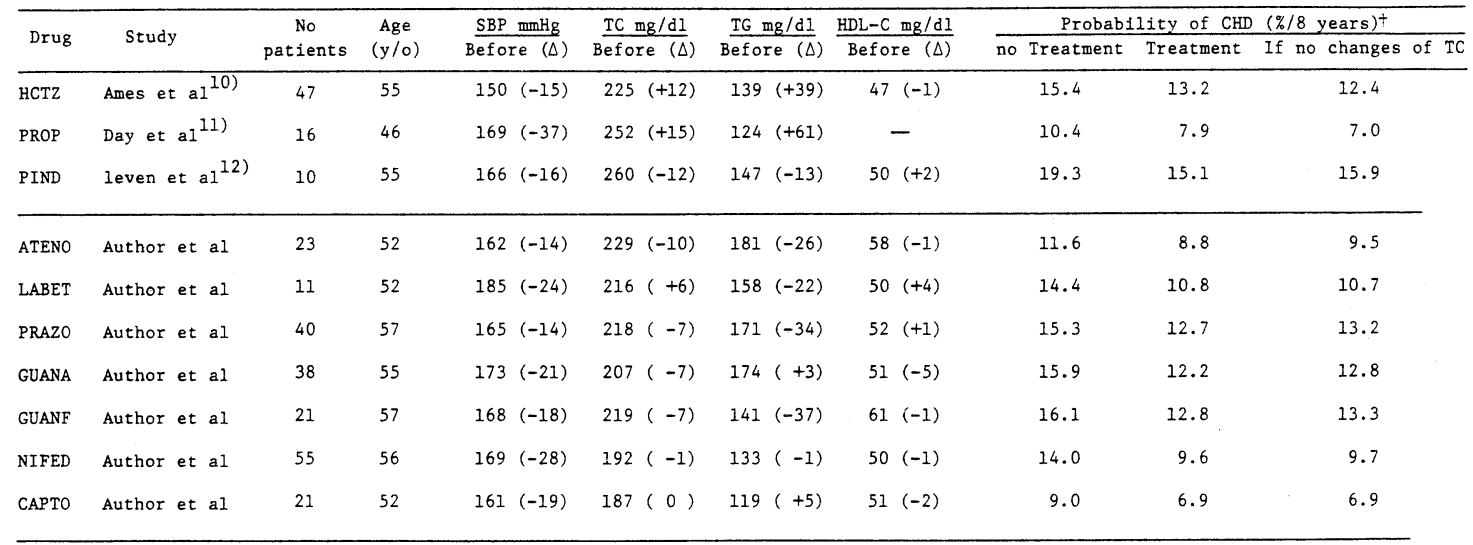

†: calculate the probability according to the Risk Table, on the assumption that patients are all men who have no other risk factor

$\Delta$ : changes during therapy

lipids and lipoproteins. In generally, adverse effects were reported with thiazide diuretics and $\beta$-blockers without ISA, desirable effects with $\alpha_{1}$-blockers, $\alpha_{2}$-agonists and ACE inhibitors, and no significant effect with loop diuretics, $\beta$-blockers with ISA, and $\mathrm{Ca}^{++}$antagonists.

Table 2 shows the probability of hypertensive patients developing CHD over 8 years, with and without drug therapy, assuming that no other risk factors are present. It is necessary to assume that the risk table is applicable to therapeutically manipulated blood pressures and serum cholesterol levels and that these values remain constant during therapy. Obviously even a small change in the serum cholesterol level has a significant effect on the probability of developing CHD and should not be ignored. There is evidence that the incidence of $\mathrm{CHD}$ also may be affected by a number of other factors, for example the levels of serum triglyceride (TG) and HDL-C, smoking habits, and glucose tolerance. Therefore, it is possible that the actual changes in serum lipids or lipoproteins with therapy may be sufficient to reduce or offset the beneficial effect of blood pressure control on the development of CHD.

In conclusion, antihypertensive drugs which have no adverse effect on lipids metabolism should be chosen for the treatment of mild to moderate hypertension.

\section{REFERENCES}

1) Veterans Administration Cooperative Study Group on Antihypertensive Agents: Effects of Treatment on Morbidity in Hypertension, JAMA, 213: 1143, 1970.

2) US Public Health Service Hospital Cooperative Study Group: Treatment of Mild Hypertension. Circ. Res. 40: (Suppl I), I-98, 1977.

4) The Australian Therapeutic Trial in Mild Hypertension: Lancet 1: 1261, 1980.

5) The Oslo Study: Treatment of Mild Hypertension: A Five Year Controlled Drug Trial. Amer J Med 69: 725, 1980.

6) Multiple Risk Factor Intervention Trial Research Group: Multiple Risk Factor Intervention Trial. JAMA, 248: 1465, 1982.

7) Medical Research Council Working Party: MRC trial of treatment of mild hypertension: principal results. Brit Med J 291: 97, 1985.

8) Mortliaty and morbidity results from the European working party on high blood pressure in the elderly trial, Lancet, i: 1349, 1985.

9) Kannel WB: Handbook of Coronary Risk Probability. American Heart Association, New York, 1973.

10) Ames RP, Hill P: Antihypertensive therapy and the Coronary heart disease. J Cardiovasc Pharm 4: (Suppl 2) $s 206,1982$.

11) Day JL, et al: Metabolic consequences of atenolol and propranolol in treatment of essential hypertension. Brit Med J 13: 77, 1979.

12) Leren P, et al: Effects of pindolol and hydrochlorothiazide on blood lipids - the oslo study. Clinical Trials Journal 18: 254, 1981. 